\section{Spontaneous remission of secondary hyperparathyroidism in patient receiving regular dialysis}

Spontaneous remission of secondary hyperparathyroidism in a patient receiving regular dialysis treatment is unusual. To our knowledge no case has been reported.

\section{Case report}

A 30-year-old man presented in 1969 with a nephrotic syndrome. Renal biopsy confirmed crescentic glomerulonephritis. He was treated with immunosuppressive drugs and later progressed to end-stage renal failure. In September 1971 regular haemodialysis was started. Apart from having an episode of pleuropericardial effusion in April 1973, which needed to be tapped, and undergoing rib resection for thoracic empyema he did well receiving home haemodialysis and could work full time. In August 1979, after developing haematuria and haemorrhage into the right kidney, which had become multicystic, he underwent right nephrectomy. Cadaveric renal transplantation was performed in November 1979, but the transplant had to be removed six months later because of persistent urinary tract infections and a ureteric leak.

Plasma calcium and inorganic phosphate concentrations and alkaline phosphatase activity in 1974 and 1975 were within normal limits. By 1976, though normocalcaemic, he had developed a raised alkaline phosphatase activity and radiological evidence of subperiosteal erosions and pepper-pot calvarium, characteristic of hyperparathyroidism. From May 1978 he was treated with 1 - $\alpha$-hydroxycholecalciferol $\left(1-\alpha-\mathrm{OHD}_{3}\right) 1 \mu \mathrm{g}$ daily, but this had to be stopped in January 1979 because of hypercalcaemia. A month later he started taking $0.25 \mu \mathrm{g}$ daily, but this was stopped after the renal transplantation.

After he began to receive home dialysis again in May 1980 his plasma calcium concentration rose progressively from $2.65 \mathrm{mmol} / 1(10.6 \mathrm{mg} / 100 \mathrm{ml})$ in June to $3.47 \mathrm{mmol} / 1(13.9 \mathrm{mg} / 100 \mathrm{ml})$ in October (figure). The plasma parathyroid hormone concentration, estimated by Dr J L H O'Riordan (Middlesex Hospital), was $960 \mathrm{ng} / \mathrm{l}$ and over $1000 \mathrm{ng} / \mathrm{l}$ in July and October 1980 , respectively (normal less than $120 \mathrm{ng} / 1$; amino-terminal specific assay).
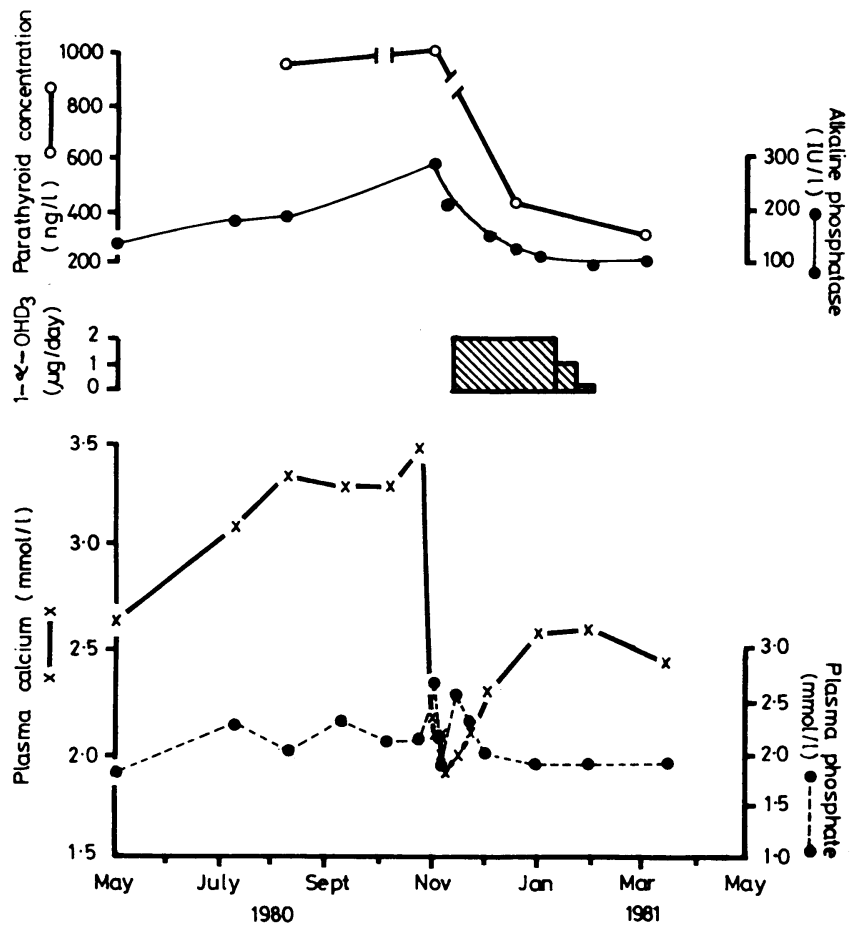

Serial blood measurements of calcium, phosphate, parathyroid hormone, and alkaline phosphatase after home haemodialysis was started again in May 1980. Hatched area indicates treatment with $1-\alpha$-hydroxycholecalciferol $\left(1-\alpha-\mathrm{OHD}_{3}\right)$

Conversion: SI to traditional units-Plasma calcium: $1 \mathrm{mmol} / 1 \approx 4 \mathrm{mg} / 100$ $\mathrm{ml}$. Plasma phosphate: $1 \mathrm{mmol} / \mathrm{l} \approx 3.2 \mathrm{mg} / 100 \mathrm{ml}$.
Parathyroidectomy was arranged but before the operation could be done he was readmitted on 21 October 1980 because of malaise associated with varying degrees of heart block, a painful throat, and dysphagia. His plasma calcium concentration had fallen within seven days from $3.47 \mathrm{mmol} / 1$ (13.9 $\mathrm{mg} / 100 \mathrm{ml})$ to $2.2 \mathrm{mmol} / 1(8.8 \mathrm{mg} / 100 \mathrm{ml})$, and seven days later it was 1.90 $\mathrm{mmol} / 1(7.6 \mathrm{mg} / 100 \mathrm{ml})$. He was placed on $1-\alpha-\mathrm{OHD}_{3} 2 \mu \mathrm{g}$ daily, resulting in a rise in plasma calcium concentration to $2.61 \mathrm{mmol} / 1(10.4 \mathrm{mg} / 100 \mathrm{ml})$ within eight weeks, by which time his cardiac rhythm had also returned to normal. The dose of $1-\alpha-\mathrm{OHD}_{3}$ was subsequently progressively reduced and was totally withdrawn on 29 January 1981 . His plasma parathyroid hormone concentration had fallen to 420 and $310 \mathrm{ng} / \mathrm{l}$ by December 1980 and April 1981 respectively. Radiological survey in October 1981 showed regression towards normal of the finger and skull appearances (Dr A Carty). He remained asymptomatic and was working full time, receiving home haemodialysis.

\section{Comment}

The clinical, biochemical, and radiological findings were typical of secondary hyperparathyroidism. Spontaneous biochemical remission has been described in primary hyperparathyroidis ${ }^{2}$ and parathyroid carcinoma. ${ }^{3}$ We have not seen any reports of remission in patients with secondary hyperparathyroidism and end-stage renal failure receiving regular haemodialysis such as is suggested by the sequence of biochemical and radiological changes in our patient. We are not sure of the exact mechanism of remission but postulate that infarction of the parathyroid glands resulted from formation of calciumphosphate protein complexes within the glands. ${ }^{4}$ The subsequent clinical wellbeing of the patient did not justify confirmatory exploration of the parathyroid.

The assays of parathyroid hormone concentration were kindly performed by $\mathrm{Dr} \mathrm{J} \mathrm{L} \mathrm{H}$ O'Riordan, Middlesex Hospital, London. We thank Linda Saxon for her secretarial help.

${ }^{1}$ Papapoulos SE, Manning RM, Hendy GN, Lewin IG, O'Riordan JLH. Studies of circulating parathyroid hormone in man using a homologous amino-terminal specific immunoradiometric assay. Clin Endocrinol $1980 ; 13: 57-67$

${ }^{2}$ Johnston CC Jr, Schnute RB. A case of primary hyperparathyroidism with spontaneous remission following infarction of the adenoma with development of hypocalcemic tetany. F Clin Endocrinol Metab 1961 ;21 : 196-200.

${ }^{3}$ Klimuik PS, Mainwaring AR. Spontaneous biochemical remission in parathyroid carcinoma. Br Med $\mathcal{f} 1980 ; 281: 1394-5$.

${ }^{4}$ Howard JE, Follis RH, Yendt ER, Connor TB. Hyperparathyroidism. Case report illustrating spontaneous remission due to necrosis of adenoma and a study of the incidence of necroses in parathyroid adenomas. F Clin Endocrinol Metab 1953;13:997-1008.

(Accepted 6 November 1981)

Liverpool Regiónal Dialysis Unit, Sefton General Hospital, Liverpool L15 2HE

R AHMAD, MB, MSC, associate specialist

N RAICHURA, MB, $\mathrm{CHB}$, senior house officer

H J GOLDSMITH, MD, FRCP, consultant nephrologist

\section{Endogenous opioid poisoning?}

A woman admitted to hospital because of a fracture of the femur developed extreme respiratory depression that responded to the opioid antagonist naloxone. It was concluded that the high opioid concentrations found in her cerebrospinal fluid were due to an endogenous met-enkephalin-like endorphin.

\section{Case report}

A 65-year-old woman fell from a bus sustaining an intertrochanteric fracture of her left femur. When admitted to hospital she was alert and well orientated. Four hours after admission she underwent an operation for insertion of a Pugh nail. She was given pethidine $50 \mathrm{mg}$ and atropine $0.4 \mathrm{mg}$ by intramuscular injection and then thiopentone $100 \mathrm{mg}$, nitrous oxide, 
halothane, and oxygen. The operation and anaesthesia were uneventful. Subsequent pain was controlled by the injection of a further $50 \mathrm{mg}$ pethidine.

The next day she had only slight pain, which was well controlled by 30 $\mathrm{mg}$ doses of dihydrocodeine by mouth. On the second postoperative day, however, she became progressively drowsy with respiratory frequency slowing to four breaths/min. Her pulse became irregular with electrocardiographic evidence of ectopic beats and right bundle-branch block. She had no focal neurological signs, but her conscious level continued to deteriorate until she responded only to painful stimuli. Computed tomography of the brain showed no abnormality apart from carotid syphon calcification. Urine output was poor and plasma urea and creatinine concentrations rose to $14.5 \mathrm{mmol} / 1(87 \mathrm{mg} / 100 \mathrm{ml})$ and $250 \mu \mathrm{mol} / 1(2.8 \mathrm{mg} / 100 \mathrm{ml})$ respectively despite apparently normal hydration (plasma sodium concentration 133 $\mathrm{mmol}(\mathrm{mEq}) / 1)$. Arterial blood gas analysis showed oxygen tension $7.9 \mathrm{kPa}$ $(59 \mathrm{~mm} \mathrm{Hg})$ and carbon dioxide tension $6.5 \mathrm{kPa}(49 \mathrm{~mm} \mathrm{Hg})$; she was treated with an inspired oxygen concentration of $35 \%$ and her arterial tension rose to $12.3 \mathrm{kPa}(92 \mathrm{~mm} \mathrm{Hg})$. Her slow, deep breathing suggested opioid overdosage, and $0.4 \mathrm{mg}$ of the opioid antagonist naloxone was given intravenously. She immediately woke and asked where she was, and respiratory frequency increased to 20 breaths $/ \mathrm{min}$. She became sleepy again over the next half hour, her respiratory frequency falling to $10 / \mathrm{min}$. A further dose of naloxone had a good but less dramatic effect.

An infusion of doxapram was almost completely ineffective; she took only six breaths/min and remained drowsy. Lumbar puncture was performed; the pressure and appearance of the fluid were normal and a sample was taken for analysis. A continuous naloxone infusion was then started. As long as her respiratory frequency was greater than $10 / \mathrm{min}$ her conscious level remained satisfactory. The figure shows the respiratory frequency and doses of drugs used. The infusion was stopped on her sixth day in hospital; respiratory frequency fell but she no longer lapsed into unconsciousness. The respiratory rate was normal by the next day. For a few days after operation she was distinctly oliguric: this improved gradually with frusemide and fluid management.

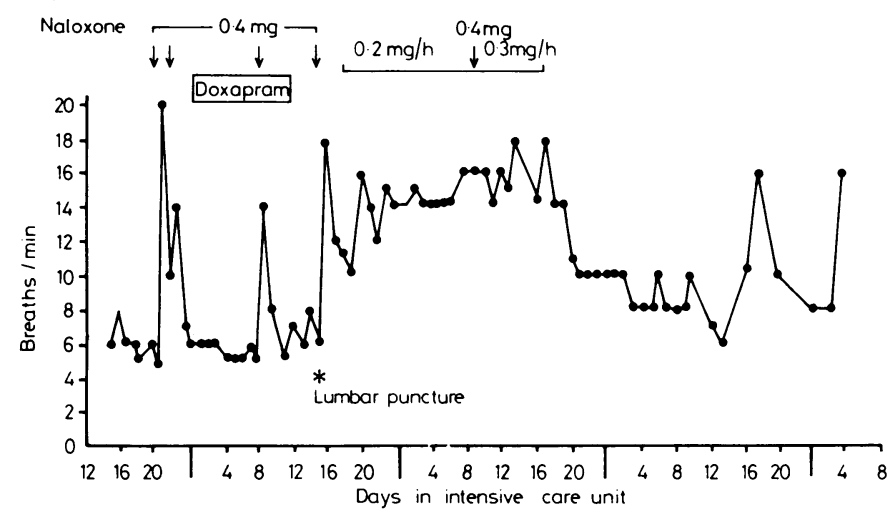

Respiratory frequency during treatment, showing individual doses of naloxone, two periods of continuous infusion, and infusion of doxapram.

Control values for methionine-enkephalin and substance $P$ in cerebrospinal fluid are in the range $0-10 \mathrm{pmol}$ met-enkephalin/1 and 20-100 pmol substance $\mathrm{P} / \mathrm{l}$ (Y Hosobuchi, unpublished observations). The concentration of metenkephalin in this sample was $>9.0 \mathrm{nmol} / 1$ and of substance $P$ at least $350 \mathrm{pmol} / \mathrm{l}$. More detailed characterisation could not be attempted as all the available material had been used.

\section{Comment}

The extreme respiratory depression in this patient responded to the opioid antagonist naloxone. Naloxone is sufficiently specific that this response indicates the presence of opioid, and she had been fully conscious both on admission and after anaesthesia and had no evidence of brain injury. We conclude that her drowsiness and respiratory depression were opioid effects. A specific radioimmunoassay showed a high cerebrospinal fluid concentration of endorphin (met-enkephalinlike material). Although we could not determine the exact nature of the material, the specificity of the assay has been described ${ }^{1}$ and the material must at least have contained the methionine-enkephalin sequence. The concentration of substance $P$ in the cerebrospinal fluid was less abnormal and could not account for the observed symptoms.

The question arises where the opioid came from. She had received two $50 \mathrm{mg}$ doses of pethidine on the day of admission. Neither caused drowsiness or respiratory depression, and after the first dose she could breathe spontaneously while under the anaesthetic. She subsequently received five doses of dihydrocodeine over 24 hours. Respiratory depression is not associated with use of this drug in moderate dosage.
Opioids may cause delayed respiratory depression; respiratory depression has occurred up to 24 hours after intrathecal injection of morphine. ${ }^{23}$ In our case the interval was about 36 hours and no drugs had been given intrathecally. The patient was still perceptibly drowsy seven days after her second dose of pethidine and six days after the last dose of dihydrocodeine. Neither pethidine nor dihydrocodeine show up in the radioimmunoassay used, which is specifically directed at peptides. The other striking feature was oliguria; no urine at all was passed on either the day of operation or the first postoperative day and the next day she produced only $18 \mathrm{ml}$. Opioids are commonly. regarded as potent stimulators of release of antidiuretic hormone,
although this view has recently been challenged. ${ }^{5}$ Diuresis in our case coincided with the use of naloxone, although there were associated changes in central venous pressure, conscious level, and arterial gas $\overline{\bar{\sigma}}$. tensions, which may have been contributory.

Given the radioimmunoassay data we must conclude that the high opioid concentrations found in her cerebrospinal fluid were caused by an endogenous met-enkephalin-like endorphin.

We thank Dr L L Iversen, director of the MRC Neurochemical Pharmacology Unit, for his help and advice in the investigation of this case and the $\vec{\omega}$ preparation of this report, and Mr A G H Murley for permission to publisho this case.

1 Clement-Jones V, Lowry PJ, Rees LH, Besser GM. Development of àn specific extracted radioimmunoassay for methionine-enkephalin in 0 human plasma and cerebrospinal fluid. F Endocrinol 1980;86:231-43.

2 Davies GK, Tolhurst-Cleaver CL, James TL. Respiratory depressionc after intrathecal narcotics. Anaesthesia 1980;35:1080-3.

${ }^{3}$ Gjessing J, Tomlin PJ. Postoperative pain control with intrathecal morphine. Anaesthesia $1980 ; 36: 268-76$.

+ Jaffe JH, Martin WR. Narcotic analgesics and antagonists. In: Goodman? LS, Gilman A, eds. Pharmacological basis of therapeutics. 5th ed. New York: MacMillan, 1975:280.

${ }^{5}$ Grossman A, Besser GM, Milles JJ, Baylis PH. Inhibition of vasopressin $-\vec{\omega}$ release in many by an opiate peptide. Lancet 1980;ii:1108-10.

(Accepted 23 September 1981)

Addenbrooke's Hospital and MRC Neurochemical Pharmacology

Unit, Cambridge CB2 2QQ

IRIS E SYMONS, MB, FFARCS, senior registrar in anaesthetics

PIERS C EMSON, MSC, PHD, senior scientist

JOHN V FARMAN, MB, FFARCS, consultant anaesthetist

\section{Serum sickness due to hair straightener}

Serum sickness, a delayed reaction to the administration of foreign protein, has been shown to be due to immune-complex deposition and inflammation mediated via the classical complement pathway. ${ }^{12}$ Clinical manifestations generally become apparent within three to 14 days after exposure to the relevant agent.

\section{Case report}

A previously fit 31-year-old West Indian woman used a proprietary hair-straightening product, Alberto Culver, for about 48 hours, noting an initial burning sensation in the treated area. Within 48 hours she had developed shortness of breath, generalised swelling of the joints and legs and a pruritic maculopapular rash that spread from the neck area over mosp of the body.

On admission she was feverish and had a symmetrical polyarthropathyo affecting particularly the wrists, metacarpal and interphalangeal joints, and both knee joints, which had moderate effusions. Shallow mucosal mouthe ulcers and palpable, tender left supraclavicular and axillary nodes werE present. Liver and spleen were not palpable, and neurological examination was unremarkable.

Laboratory results showed haemoglobin concentration $11.4 \mathrm{~g} / \mathrm{dl}$; white cell count $6.8 \times 10^{9} / 1$ with normal differential and picture; and erythrocyte̊ sedimentation rate $77 \mathrm{~mm}$ in first hour. Repeat blood cultures, viral screening antistreptolysin-O titre, liver function tests, protein electrophoresis, PaulBunnell test, serum hepatitis antigen, screening for brucella, serum Wasser mann reaction, urine microscopy, sickle-cell screening, and malaria studies were all negative or yielded no useful information. Rheumatoid and anti nuclear factor tests were negative and $\operatorname{IgM}$ concentration was normal aE $198 \mathrm{IU} / \mathrm{ml}$ (normal $55-230 \mathrm{IU} / \mathrm{ml}$ ), but $\mathrm{IgG}$ was raised at $260 \mathrm{IU} / \mathrm{mL}$. (normal $75-200 \mathrm{IU} / \mathrm{ml}$ ) and $\mathrm{IgA}$ raised at $246 \mathrm{IU} / \mathrm{ml}$ (normal 45-200 IU $/ \mathrm{ml}) \stackrel{\mathrm{C}}{?}$ 